\title{
INVESTOR'S EXPECTED PROFIT FROM VIATICAL SETTLEMENTS
}

\author{
JOANNA DĘBICKA, STANISŁAW HEILPERN \\ Wroclaw University of Economics, Faculty of Management, Computer Science and Finance, \\ Department of Statistics, Komandorska 118/120, 53-345 Wrocław, Poland \\ email: joanna.debicka@ue.wroc.pl, stanislaw.heilpern@ue.wroc.pl
}

\begin{abstract}
For an insured person who needs money because of suffering from a terminal illness that requires costly diagnosis and treatment, the easiest way of receiving money from life insurance is to withdraw from the contract of insurance. Then the insurer is obliged to pay the surrender value of policy. It appears that there is another possibility for the insured to receive prior financial gratification from life insurance. The insured can sell his policy on the secondary market of life insurance (the viatical market). In such a situation he obtains an amount that is greater than the surrender value (and less than the death benefit). Then the viatical company takes a fee for the insurance premiums, and in case of death of the insured gets the death benefits. Such agreements to resell the rights to death benefits are offered to people who have become terminally ill (viatical settlement). The aim of the paper is to study the influence of the moment of falling ill (compared to the age and sex of the insured and duration of insurance) on the expected profit of the viatical company. For this purpose, we apply the methodology used by insurance companies in the valuation of the contract.
\end{abstract}

Key words: viatical market, life insurance, multistate model,

JEL Codes: G22, G120, C41

\section{DOI: 10.15611/amse.2017.20.08}

\section{Introduction}

The primary and secondary insurance market is constantly expanding. There are various contracts which take into account various situations that may arise in life, such as a serious illness, in case of which the priorities of the insured person may change considerably (c.f. Trinkaus, Giacalone, 2002.). In particular, it may be that the death benefit becomes less important while the life benefit becomes the most significant. On the insurance market there are different kinds of solutions to protect the insured against financial problems in this difficult situation. An insured person can lapse his policy and obtain the cash surrender value (CSV) from the insurer, or resell his right to the policy and obtain the viatical settlement payment (VSP) from the investor (see Figure 1).

Surrender values are set in the primary market of life insurance and correspond to the surplus value that builds up in policies over time. For the surrender of his whole-life policy, a policyholder usually receives roughly the amount he has paid to the insurance company on condition that is does not exceed actuarial value of the insurance costs. In case of a short term-life policy, premiums are calculated to cover the projected mortality risk associated with a policyholder over the life of the policy. Because there is no buildup of value in a term policy, the surrender value is zero. Note that the insured has the right to the surrender value, but usually only after 2-3 years of the insurance contract. Moreover, the existence of a surrender value for a policy does not oblige an insured to resell his policy to the life insurance company that had issued the policy. A policyholder has the right to transfer his ownership of the policy 
to another person on a secondary market of life insurance policies and it does not depend on whether the policy has a surrender value or it not.

Figure 1: A scheme of the primary and secondary insurance market.

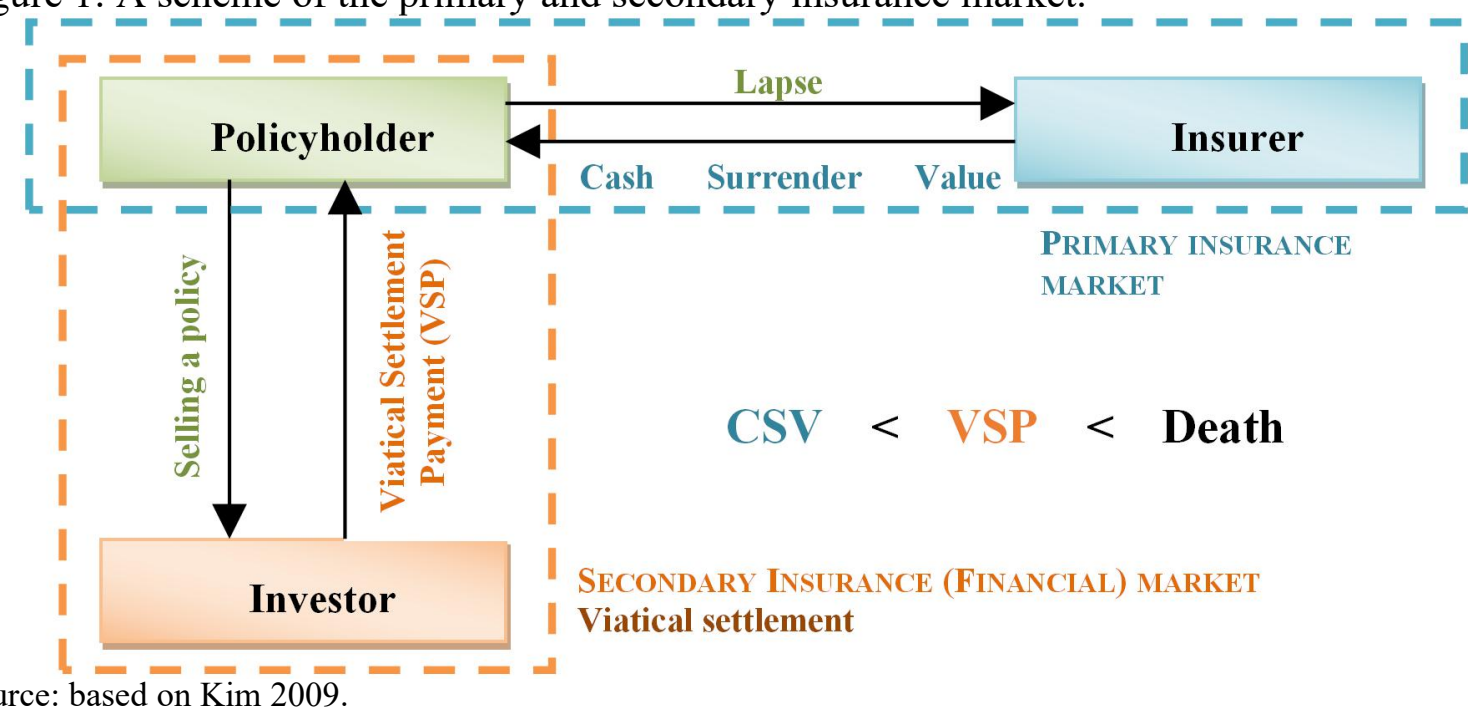

Note that premiums are calculated based on the assumption of an ordinary health condition and so are the surrender values. In a situation that an insured health suddenly deteriorates, his life expectancy is curtailed, the present actuarial value of the policy will be much higher than for a person in good health condition. Then surrender values based on a uniform assumption of ordinary health are low compared to the actual policy value for an individual with impaired health. If the insurer is the only repurchaser of his own policy, the policyholder cannot bargain effectively over the surrender value. If there is other potential buyer for the policy, the situation is changing. An investor (it is often a viatical company) can offer VSP which is higher than the CSV but does not exceed the death benefit.

A very important issue of the financial analysis of the viatical contract is the analysis of the investor's expected profit. The relevant elements of the set of the contract terms (VSP, insurance premiums, type of dread disease) allow to determine the range of profit, which is taken into account in designing of viatical contract. The aim of the paper is to study the influence of the moment of falling ill (compared to the age and sex of the insured and duration of insurance) on the range of the expected profit of the viatical company.

For this purpose, we apply the methodology used by insurance companies in the valuation of the contract (c.f. Dębicka, 2013; Dębicka, Heilpern, Marciniuk, 2016). Especially, we recommend multiple state modelling for designing and implementing viatical contracts. This methodology is commonly used in calculation of actuarial values of different types of life and health insurances and is developed for the discrete-time model (where insurance payments are excercised at the end of time intervals). Based on a modified multiple state model (or extended multiple state model) we derive a matrix formula for the highest and lowest level of the investor's expected profit (for every moment of the insurance period). This approach to costing contracts not only makes calculations easier, but also enables us to factorize the stochastic nature of the evolution of the insured risk and the interest rate, which can be observed in the derived formulas.

The paper is organized as follows. In Section 2 we describe the modified multiple state model and its probabilistic structure for viatical contracts. This modification allows us to use matrix-form approach to calculate investor's expected profit. In Section 3 we derive general matrix expressions for the highest and lowest level of the investor's expected profit. Section 4 
considers a case study of viatical contracts for the insured with lung cancer. The results obtained in Section 3 are applied to costing of viatical contracts based on the actual data for the Lower Silesian Voivodship in Poland. Conclusions have been included in Section 5.

\section{Modeling viatical contracts}

The viatical contracts state that the benefit is paid on diagnosis of a specified condition. This is understandable, because this type of contract is sensitive to the development of medicine, not all dread diseases are as mortal as a few years ago. Thus investors introduce strict conditions relating to severe diseases for the right to repurchase the rights to death benefit. He decides to purchase insurance rights based not only on the diagnosis but also on the disease stage that directly depends on the expected future lifetime of a sick person. Then the investor has to take into account that probability of death of a dread disease sufferer depends on the duration of the disease.

Let an $x$-years old person buy the whole-life insurance. The term of the policy is equal to $\omega-x$, where $\omega$ denotes the limit age of the insured. In accordance with conditions of the contract in the event of death, the insurer pays the death benefit $\mathrm{c}$ to the endowed person. The policyholder is obliged to pay annual premiums $(p)$ at the beginning of the first $m$ years of the insurance period $(m \leq \omega-x)$. We assume that the insured becomes terminally ill in the $k$-th year of the insurance period $(k=1,2, \ldots, \omega-x)$. It means that at the age of $x+k$, he could resell his insurance.

To model viatical contracts we use multiple state model $(S, T)$, where $S$ is a state space and $T$ denotes a set of direct transitions between states of the state space (cf. Dębicka, 2013; Haberman and Pitacco, 1999). Based on the model for critical illness insurances introduced by Dębicka, Zmyślona, (a), we construct the multiple model with the state space $S=\{1,2, \ldots, 5\}$, where the meaning of the states is as follows:

1 - the insured is terminally sick and his expected lifetime is less than 4 years

2 - the insured is terminally sick and his expected lifetime is less than 3 years

3 - the insured is terminally sick and his expected lifetime is less than 2 years

4 - the insured is terminally sick and his expected lifetime is less than 1 years

5 - the insured died being terminally sick with dread disease.

In stages 1- 4 remission of the disease is very unlikely. Moreover, that states are reflex (that is strictly transitional and after one unit of time, the insured risk leaves this state). Determination of the four states for the alive insured person results from the fact that typically an investor buy the rights to the death benefit when an expected future lifetime of the sick insured is no longer than four years or, in some cases, two years (depending on medical circumstances). The difference results from the definition of a terminally ill person. On the one hand, for example the term terminally ill in the context of health care refers to a person who is suffering from a serious illness and whose life is not expected to go beyond 2 years at the maximum. On the other hand, the HIV+ patients with more than 4,5 years of life expectancy, are treated as patients in a relatively good health.

The graphic representation of the multiple state model $(S, T)$ is shown in Figure 2a, where circles represent the states and arcs correspond to direct transitions between states. Next to the arcs we marked benefits related to the transition between states, where $\mathrm{c}$ is a given lump sum (death benefit) and by $\alpha \in[0,1]$ we denote the so called resale parameter. If $\alpha=0$, then the model describes a situation that the viatical contract has not been completed. If $0<\alpha<1$, then the model describes the partial resale of rights to the death benefit. For $\alpha=1$, the model implies that the investor bought the rights to the whole death benefit. Namely, the investor's commitments to the insured (VSP) and the insurer $(p)$ are marked in circles. 
Figure 2: A multiple state model for viatical contracts.

a. MSM with investor's cash flows

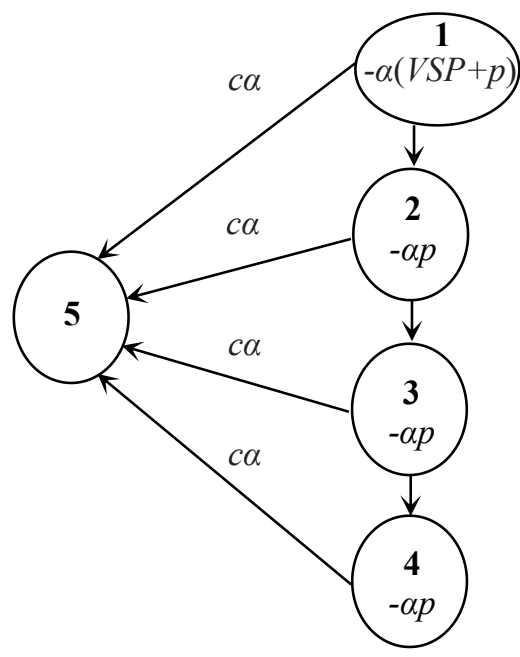

b. MMSM with investor's cash

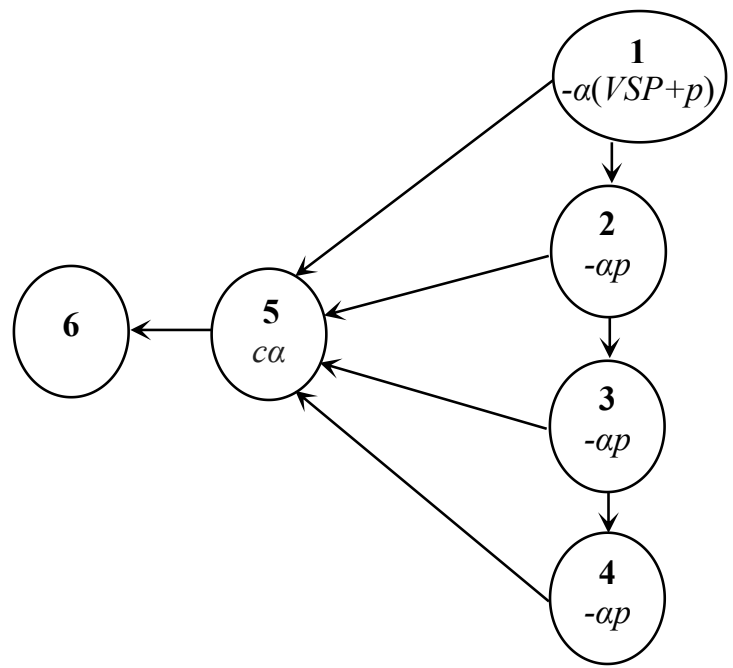

Source: own elaboration.

Note that all benefits under the viatical contract correspond to cash flows connected with transition between states (compare Figure 2a). Observe that for such a type of benefit the information that the insured risk is at moment $k$ in a particular state is not enough to determine the benefit at time $k$, because we need additional information about where the insured risk was at moment $k$-1. Matrix is a two-dimensional structure, thus it is not possible to determine the exact moment of realization of lump sum benefit by using three pieces of information. For this purpose, we have to modify the model for the viatical contract, replacing lump sum benefits by benefits associated with the insured risk staying in particular states. Following the procedure of modification of the multiple state model presented in Dębicka, 2013, we introduce a new state 6 which means that insured has been dead for at least one year. State 5 (the insured died being terminally sick with dread disease) becomes the reflex state. Thus the new state space consists of six states $\left(N^{*}=6\right)$. As a result, the modified multiple state model $\left(S^{*}, T^{*}\right)$ for viatical contracts assumes the form presented in Figure $2 \mathrm{~b}$. Note that now the benefits are the cash flows connected with the insured risk staying in considered states, which uniquely determine the moment of paying the benefit.

Let $n$ denote the term of the contract (or the contract period). Because states 1 to 4 are reflex state then the term of viatical contract is equal to 4 years $(n=4)$. Let the evolution of the insured risk for $\left(S^{*}, T^{*}\right)$ be described by a discrete-time stochastic process $\left\{X_{k}^{*}(t) ; t \in\{0,1,2,3,4\}\right\}$ where $k$ is a year of the insurance period in which the insured became seriously ill. We assume that $\left\{X_{k}^{*}(t) ; t \in\{0,1,2,3,4\}\right\}$ is a nonhomogeneous Markov chain with $\left\{\mathbf{Q}_{k}^{*}(t)\right\}_{t=0}^{3}$, where $\mathbf{Q}_{k}^{*}(t)=\left(q_{i j}^{*}(t ; k)\right)_{i, j=1}^{6}$ and $q_{i j}^{*}(t ; k)=P\left(X_{k}^{*}(t+1)=j \mid X_{k}^{*}(t)=i\right)(\mathrm{cf}$. Christiansen, 2012; Djehjche, 2011). In particular, for $t \in\{0,1,2,3\}$ and $x+k+t \leq \omega-n$, the transition matrix has the following form 


$$
\mathbf{Q}_{k}^{*}(t)=\left(\begin{array}{cccccc}
0 & q_{12}^{*}(t ; k) & 0 & 0 & q_{15}^{*}(t ; k) & 0 \\
0 & 0 & q_{23}^{*}(t ; k) & 0 & q_{25}^{*}(t ; k) & 0 \\
0 & 0 & 0 & q_{34}^{*}(t ; k) & q_{35}^{*}(t ; k) & 0 \\
0 & 0 & 0 & 0 & 1 & 0 \\
0 & 0 & 0 & 0 & 0 & 1 \\
0 & 0 & 0 & 0 & 0 & 1
\end{array}\right) .
$$

For $t$ such that $x+k+t \geq \omega-n$ matrices $\mathbf{Q}_{k}^{*}(t)$ consists of rows that have only zero elements, due to a shorter duration of the contract. The transition probabilities in $\mathbf{Q}_{k}^{*}(t)$ can be determined using a multiple increment-decrement table (or multiple state life table) for particular dread diseases (c.f. Dębicka, Zmyślona, (a))

Let matrix $\mathbf{D}_{k}$ consist of probabilities of process $\left\{X_{k}^{*}(t)\right\}$ staying at states at each moment of the contract period under the assumption that the insured is at the age of $x+k$

$$
\mathbf{D}_{k}=\left(\begin{array}{c}
\mathbf{P}_{k}^{T}(0) \\
\mathbf{P}_{k}^{T}(1) \\
\mathbf{P}_{k}^{T}(4)
\end{array}\right) \in \mathfrak{R}^{5 \times 6}
$$

where $\mathbf{P}_{k}^{T}(t)=\left(P\left(X_{k}^{T}(t)=1\right), P\left(X_{k}^{T}(t)=2\right), \ldots, P\left(X_{k}^{T}(t)=6\right)\right)$ and $\mathbf{P}_{k}^{T}(0)=(1,0,0,0,0,0) \quad$ is a vector of initial distribution. Based on $\left\{\mathbf{Q}_{k}^{T}(t)\right\}_{t=0}^{3}$ we describe columns of matrix $\mathbf{D}_{k}$ as follows

$$
\mathbf{P}_{k}^{T}(t)=\mathbf{P}_{k}^{T}(0) \prod_{s=0}^{t-1} \mathbf{Q}_{k}^{*}(s) .
$$

The matrix $\mathbf{D}_{k}$ can be used in actuarial values calculations as shown in the next sections.

\section{Investor's expected profit}

Valuation of whole life insurance contract. We assumed that $x$ - years old person bought the whole-life insurance and the insurance period is $\boldsymbol{\omega}-\boldsymbol{x}$. In the event of death, the insurer pays the endowed the death benefit $\mathrm{c}$. The annual premiums $p$ paid at the beginning of the first $m$ years of the insurance period $(\boldsymbol{m} \leq \boldsymbol{\omega}-\boldsymbol{x})$ may be calculated in the classical way (cf. Bowers \& all, 1986) or on the basis of matrix formulas (cf. Dębicka, 2013; Dębicka, Zmyślona, (b)).

Let $\mathbf{C S V}=(\operatorname{CSV}(0), \operatorname{CSV}(1), \ldots, \operatorname{CSV}(\omega-x))^{T}$ be the vector of cash surrender values in the whole insurance period. Generally, the cash surrender value in life insurances is defined as the percentage of mathematical reserve created for future benefits. The premium reserve belongs to the policyholder who has the right to get the so-called "overpaid premium" in relation to the amount of risk in the early years of the insurance. After deducting the cost of the insurance, the surrender value is obtained. Since the insurer establishes his costs, it is not possible to determine the exact value of CSV. Since the purpose of this article is to determine the possible range of an investor's profit, we adopt some assessment of CSV. In this article, we assume that the surrender value is equal to the net premium reserve. In practice, a net premium reserve is higher than the surrender value at each moment of the insurance contract. This 
allows to estimate the minimum of viatical settlement payments (VSP). Under this assumption we have

$$
\mathbf{C S V}=\mathbf{V}=(V(0), V(1), \ldots, V(\omega-x))^{T},
$$

where $\mathbf{V}$ is the vector of net premium reserves in the whole insurance contract. Analogously to calculation of premiums, a net premium reserve at moment $k$ may be calculated in the classical way (cf. Bowers \& all, 1986) or on the basis of matrix formulas (cf. Dębicka, Heilpern, Marciniuk, 2016).

Investor's Expected Cost of Premiums. We assume that the insured became terminally ill in the $k$-th year of the insurance period $(k=1,2, \ldots, \omega-x)$ and at the age of $x+k$, he resells the whole or a part of his insurance. After the purchase of an insurance, the investor is obliged to pay the total $(\alpha=1)$ or a part of $(0<\alpha<1)$ the premium for the insurance, which is the cost of investment.

Let $E C_{\alpha}(k)$ denote the investor's expected cost of premiums at the beginning of $k$-th $y e a r$ if the policyholder at that moment resell $\alpha$ part of his rights to the death benefit. $E C_{\alpha}(k)$ is the expected value of premiums accumulated at the moment $k$, which the investor will pay on condition that the insured will be alive. Thus we have

$$
E C_{\alpha}(k)=\sum_{t=0}^{3}\left(-\alpha p v^{t} P\left(X_{k}^{*}(t)=t+1\right)\right)=\alpha \sum_{t=0}^{3}\left(-p v^{t} P\left(X_{k}^{*}(t)=t+1\right)\right)=\alpha \cdot E C(k),
$$

and $\mathbf{E C}_{\alpha}=\left(E C_{\alpha}(0), E C_{\alpha}(1), \ldots, E C_{\alpha}(\omega-x)\right)^{T}=\alpha \cdot \mathbf{E C}$, where $\mathbf{E C}$ is the vector of the investor's expected costs for each moment of insurance period in case of buying rights for the whole death benefit. Based on an modified multiple state model presented in Figure $2 \mathrm{~b}$ and applying matrix notation to the valuation of an investor's expected cost of premiums (c.f. Dębicka, 2013), we obtain

$$
E C(k)=\mathbf{M}_{I}^{T} \operatorname{Diag}\left(\mathbf{C}_{\text {out }} \mathbf{D}_{k}^{T}\right) \mathbf{S},
$$

where $\mathbf{M}_{I}=\left(1, v, v^{2}, v^{3}, v^{4}\right)^{T}$ is the vector of discount functions described for an investor's interest rate, and cash flow matrix $\mathbf{C}_{\text {out }}$ consisting only of outflow from the investor's fund has the following form

$$
\mathbf{C}_{\text {out }}=\left(\begin{array}{cccccc}
-p & 0 & 0 & 0 & 0 & 0 \\
0 & -p & 0 & 0 & 0 & 0 \\
0 & 0 & -p & 0 & 0 & 0 \\
0 & 0 & 0 & -p & 0 & 0 \\
0 & 0 & 0 & 0 & 0 & 0
\end{array}\right)
$$

Furthermore, $\mathbf{S}=(1,1,1,1,1)^{T}$ and for any matrix $\mathbf{A}=\left(a_{i j}\right)_{i, j=1}^{n+1}$, let Diag (A) be a diagonal matrix which diagonal elements consist of a diagonal of matrix $\mathbf{A}$.

Investor's Expected Benefits. After the purchase of an insurance, the investor has rights to the total $(\alpha=1)$ or part of $(0<\alpha<1)$ the benefit after the death of the insured person. 
Let $E B_{\alpha}(k)$ denote the investor's expected benefit at the beginning of $k$-th year if the policyholder at that moment resells $\alpha$ percentage of his rights to the death benefit. We have

$$
E B_{\alpha}(k)=\sum_{t=1}^{4} \alpha c v^{t} P\left(X_{k}^{*}(t)=5\right)=\alpha \sum_{t=1}^{4} c v^{t} P\left(X_{k}^{*}(t)=5\right)=\alpha \cdot E B(k),
$$

and $\mathbf{E} \mathbf{B}_{\alpha}=\left(E B_{\alpha}(0), E B_{\alpha}(1), \ldots, E B_{\alpha}(\omega-x)\right)^{T}=\alpha \cdot \mathbf{E B}$, where $\mathbf{E B}$ is the vector of the investor's expected benefits for each moment of insurance period in case of buying rights for the whole death benefit. Analogously to investor's expected benefits we obtain

$$
E B(k)=\mathbf{M}_{I}^{T} \operatorname{Diag}\left(\mathbf{C}_{i n} \mathbf{D}_{k}^{T}\right) \mathbf{S},
$$

where the cash flow matrix $\mathbf{C}_{\text {in }}$ consists only of inflow to the investor fund and has the following form

$$
\mathbf{C}_{i n}=\left(\begin{array}{llllll}
0 & 0 & 0 & 0 & 0 & 0 \\
0 & 0 & 0 & 0 & c & 0 \\
0 & 0 & 0 & 0 & c & 0 \\
0 & 0 & 0 & 0 & c & 0 \\
0 & 0 & 0 & 0 & c & 0
\end{array}\right) .
$$

Range of VSP. The investor's profit depends on the VSP which he is willing to pay the policyholder for the repurchase of rights to death benefits. The investor can offer VSP which is higher than the CSV but it does not exceed the death benefit. In particular, VSP has to be less than the difference between the expected value of benefits and premiums. Thus (based on assumption (3) ) we have

$$
V(k)<V S P(k)<E B(k)+E C(k),
$$

where $\mathbf{V S P}=(\operatorname{VSP}(0), \operatorname{VSP}(1), \ldots, \operatorname{VSP}(\omega-x))^{T}$ is the vector of viatical settlement payment during the whole insurance period.

Range of Investor's Expected Profits. The investor's expected profit $E P_{\alpha}(k)$ at the beginning of $k$-th year is the difference between the expected benefits, and the sum of the expected cost of premiums and the amount to be paid for the repurchase of rights to death benefit or part thereof. Thus

$$
E P_{\alpha}(k)=E B_{\alpha}(k)+E C_{\alpha}(k)-\alpha V S P(k) .
$$

Applying (4) - (7) to (9) we obtain

$$
\begin{aligned}
E P_{\alpha}(k) & =\alpha\left(\mathbf{M}_{I}^{T} \operatorname{Diag}\left(\mathbf{C}_{i n} \mathbf{D}_{k}^{T}\right) \mathbf{S}+\mathbf{M}_{I}^{T} \operatorname{Diag}\left(\mathbf{C}_{\text {out }} \mathbf{D}_{k}^{T}\right) \mathbf{S}-\operatorname{VSP}(k)\right) \\
& =\alpha\left(\mathbf{M}_{I}^{T} \operatorname{Diag}\left(\mathbf{C D}_{k}^{T}\right) \mathbf{S}-\operatorname{VSP}(k)\right) \\
& =\alpha \cdot \operatorname{EP}(k),
\end{aligned}
$$

where $E P(k)=E P_{1}(k)$ and $\mathbf{C}=\mathbf{C}_{\text {in }}+\mathbf{C}_{\text {out }}$.

Note that based on (8) we can determine the upper and lower limits (range) of the expected profits of the investor 
and

$$
E P_{\alpha}^{M A X}(k)=\alpha\left(\mathbf{M}_{I}^{T} \operatorname{Diag}\left(\mathbf{C D}_{k}^{T}\right) \mathbf{S}-V(k)\right)
$$

$$
E P_{\alpha}^{M I N}(k)=\alpha\left(\mathbf{M}_{I}^{T} \operatorname{Diag}\left(\mathbf{C D}_{k}^{T}\right) \mathbf{S}-\mathbf{M}_{I}^{T} \operatorname{Diag}\left(\mathbf{C D}_{k}^{T}\right) \mathbf{S}\right)=\alpha \cdot 0=0 .
$$

Taking into account (10) and (11), the investor's expected profit, assuming that he bought the rights to the whole death benefit, is thought to be in the following range

$$
0<E P(k)<\mathbf{M}_{I}^{T} \operatorname{Diag}\left(\mathbf{C D}_{k}^{T}\right) \mathbf{S}-V(k) .
$$

Note that

$$
0<E_{\alpha} P(k)<\alpha\left(\mathbf{M}_{I}^{T} \operatorname{Diag}\left(\mathbf{C D}_{k}^{T}\right) \mathbf{S}-V(k)\right)
$$

if the investor bought the rights to the part of death benefit.

\section{Applications}

Severe diseases include cancer. In particular, lung cancer belongs to the group of tumours characterized by the highest mortality rates and a relatively short survival time after the diagnosis. It means that lung cancer is a good example of a deadly disease that could be the cause of reselling insurance. Based on Dębicka, Zmyślona, (a) we describe the state space $S^{*}=\{1,2, \ldots, 6\}$, where the meaning of the states is as follows:

1 - insured is suffering from cancer for a year after diagnosis of metastases,

2 - insured is suffering from cancer for the second year after diagnosis of metastases,

3 - insured is suffering from cancer for a third year after diagnosis of metastases,

4 - insured is suffering from cancer for a fourth year after diagnosis of metastases,

5 - insured died being sick with cancer with diagnosed metastases,

6 - insured has been dead for at least one year.

In order to estimate elements of transition matrix $\left\{\mathbf{Q}_{k}^{*}(t)\right\}_{t=0}^{3}$ we used the multiple incrementdecrement table presented in Dębicka, Zmyślona (c).

We assume that the lump sum paid when the insured dies is equal to 1 i.e. $c=1$. Moreover, the constant period premium $p$ is paid when the insured is alive i.e. at states 1- 4. Premiums and the vector of net premium reserves $\mathbf{V}$ are calculated under the assumption that the interest rate is constant and equals $1 \%$ (this actuarial values insurer calculate securely with some surplus). Moreover, $\mathbf{M}_{I}$ is described assuming that the interest rate is $1 \%$. The determination of investor's profit and loses is based on the more realistic (means greater) interest rate (c.f. Dębicka, Heilpern, Marciniuk, 2016).

We start with the whole insurance contract for a 20-year old person $(x=20)$. Epidemiological data shows that the morbidity rate is several times higher in male population than in female. Fortunately, the application of the European Union Directive, which does not distinguish gender in actuarial calculating, is not applicable in the viatical market, so we decided to analyze the investor's expected profit separately for male and female. Three scenarios of paying premiums are analyzed when the premium is paid by the whole insurance period $(m=80)$, up to 80 years of the insured age $(m=60)$ and up to the approximate age of retirement $(\mathrm{m}=40)$. Premiums determined on the basis of Polish Life Tables 2008 are presented in Table 1 for each scenario.

Note that premiums for men are higher than premiums for women. Moreover, the shorter the period of premium payment, the more increased the premium.

Under the introduced assumption, the range of viatical settlement payment (c.f. (8)) and the corresponding range of the investor's expected profit (c.f. (12) ) are presented in Figure 3. Values are calculated for 20 year old man $(\mathrm{x}=20)$. Note that the size of $\operatorname{VSP}(k)$ and $\operatorname{EP}(k)$ depends on the duration of the insurance contract. The upper limit of the range $\operatorname{VSP}(k)$ 
increases when all required insurance premiums have been paid. On the other hand, the lower limit of the range $\operatorname{VSP}(k)$ is greater if the period of payment of contributions is shorter. This directly affects the increase in the resale value. The investor is forced to offer a higher amount to the insured which, in turn, reduces the expected profits that the investor can achieve.

Figure 3: Ranges of viatical settlement payment and investor's expected profits for whole life insurance (insured: 20 years old man).
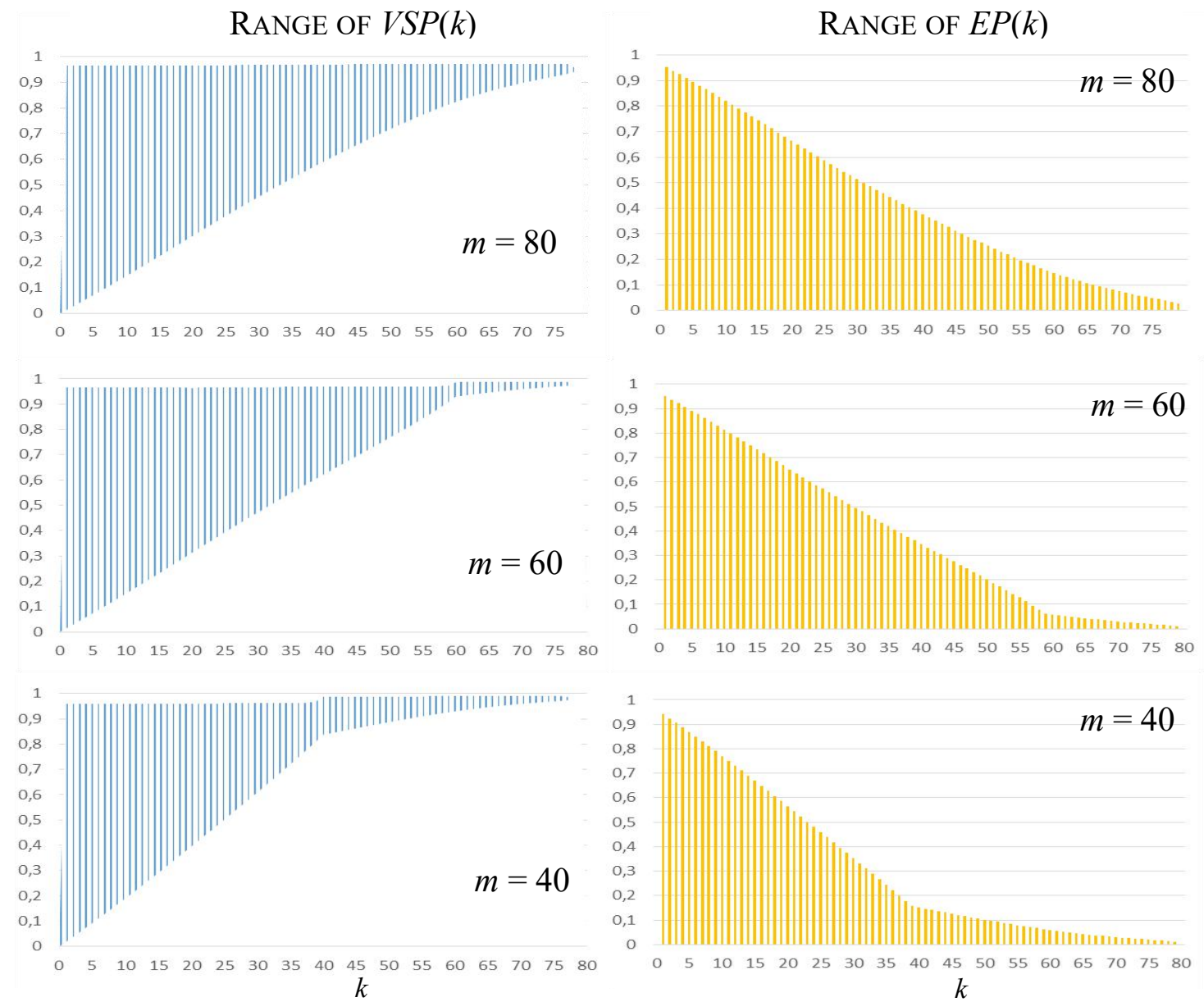

Source: own elaboration

The shapes of graphs contained in Figure 3, in case of women are similar. Therefore, Figure 4 presented only percentage changes in the investor's expected profit for women $E P^{\mathrm{W}}(k)$ in relation to the investor's expected profit for men $E P^{\mathrm{M}}(k)$ i.e.

$$
\left(\frac{E P^{W}(k)}{E P^{M}(k)}-1\right) \cdot 100 \%
$$

The shorter the insurance contract lasts, the smaller amount of money to repurchase the right to death benefits may be offered by the investor (Figure 5), which means higher expected profits for him (Figure 6). For women graphs contained in Figure 6 and conclusions are similar.

Analysis of plots in Figure 4 shows that the gender and actual insured age $(20+k)$ is important from the point of view of the investor's expected profits. It is not surprising because the incidence rate strongly depends on these two features. It is already visible when we analyze the height of premiums for insurance (cf. Table 1). 
Table 1: Premiums for the whole life insurance contracts (insured: 20 years old man and woman).

\begin{tabular}{lccc}
\hline premium $(\boldsymbol{p})$ & $\boldsymbol{m}=\mathbf{8 0}$ & $\boldsymbol{m}=\mathbf{6 0}$ & $\boldsymbol{m}=\mathbf{4 0}$ \\
\hline man & 0,01481482 & 0,01532241 & 0,01896072 \\
woman & 0,01204897 & 0,01285290 & 0,01680619 \\
\hline
\end{tabular}

Source: own elaboration.

If the premiums are paid throughout the whole period of insurance $(m=80)$, it is more advantageous for the investor to repurchase the rights to the death benefit when the insured is a man. Apart from the period between 90 and 100 years of age, where it is preferable to buy insurance from a woman. This short period of time is related to the specifics of the course of disease due to a different structure of morbidity and mortality associated with lung cancer. In case of premiums payable in a shorter period of time, by purchasing the right to benefit from the woman, the investor can count on bigger profits at any time during the insurance contract.

Figure 4: Percentage changes in the investor's expected profit for women in relation to the investor's expected profit for men (insured: 20 year-old man and 20 year-old woman).

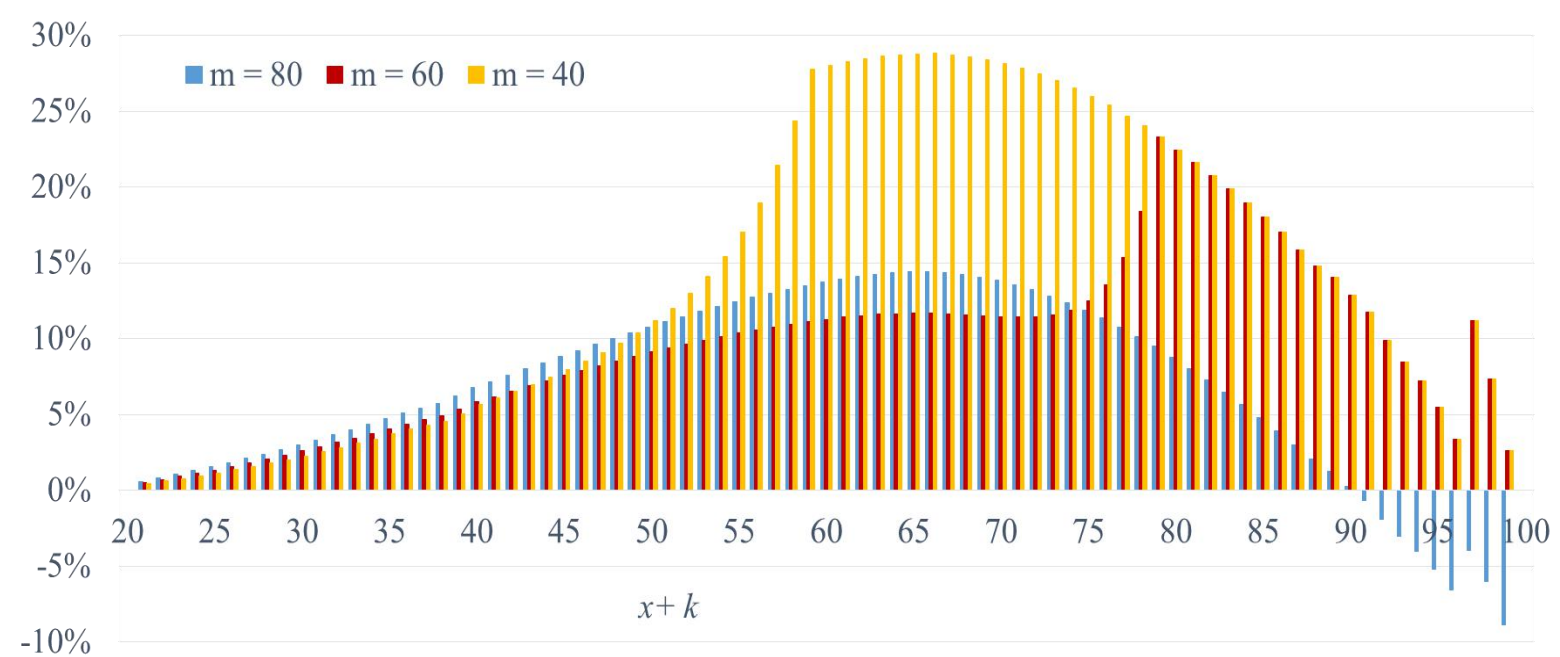

Source: own elaboration.

Note that, independently on sex, in the age group of 20 to 40 years, lung cancer occurs extremely rarely, therefore the percentage changes in the investor's expected profit for women in relation to the investor's expected profit for man do not exceed 5- 7 percent. The lung cancer incidence begins to increase after the age of fifty and the peak incidence occurs at the sixth and seventh decades of life and at that period we observe quite big differences between investor's expected profit for women and men.

Table 2: Premiums for the whole life insurance contracts paid by the whole insurance period (insured: 20, 40, 60 years old man).

\begin{tabular}{lccc}
\hline age at entry & $\boldsymbol{x}=\mathbf{2 0}$ & $\boldsymbol{x}=\mathbf{4 0}$ & $\boldsymbol{x}=\mathbf{6 0}$ \\
\hline premium $(\boldsymbol{p})$ & 0,014771432 & 0,025355986 & 0,050480059 \\
\hline
\end{tabular}

Source: own elaboration.

The moment of becoming ill is always random, and the value of viatical settlement payment depends mostly on the duration of the insurance contract at the moment of being affected by a severe disease. In Figure 5, the differences between upper and lower limits of the ranges $\operatorname{VSP}(\mathrm{k})$ for insurance contracts for men aged 20, 40 and 60 years are presented. We 
assume that the premiums are paid throughout the whole period of insurance. Figure 6 presents the range of possible investor's expected profits for these contracts.

The differences between upper and lower limits of the ranges VSP $(\mathrm{k})$ presented in Figure 5 result from the volume of insurance premiums. The older the insured and the shorter the insurance period, the higher the premium (cf. Table 2).

Figure 5: Ranges of viatical settlement payment for the whole life insurance (insured: 20, 40, 60 years old man).

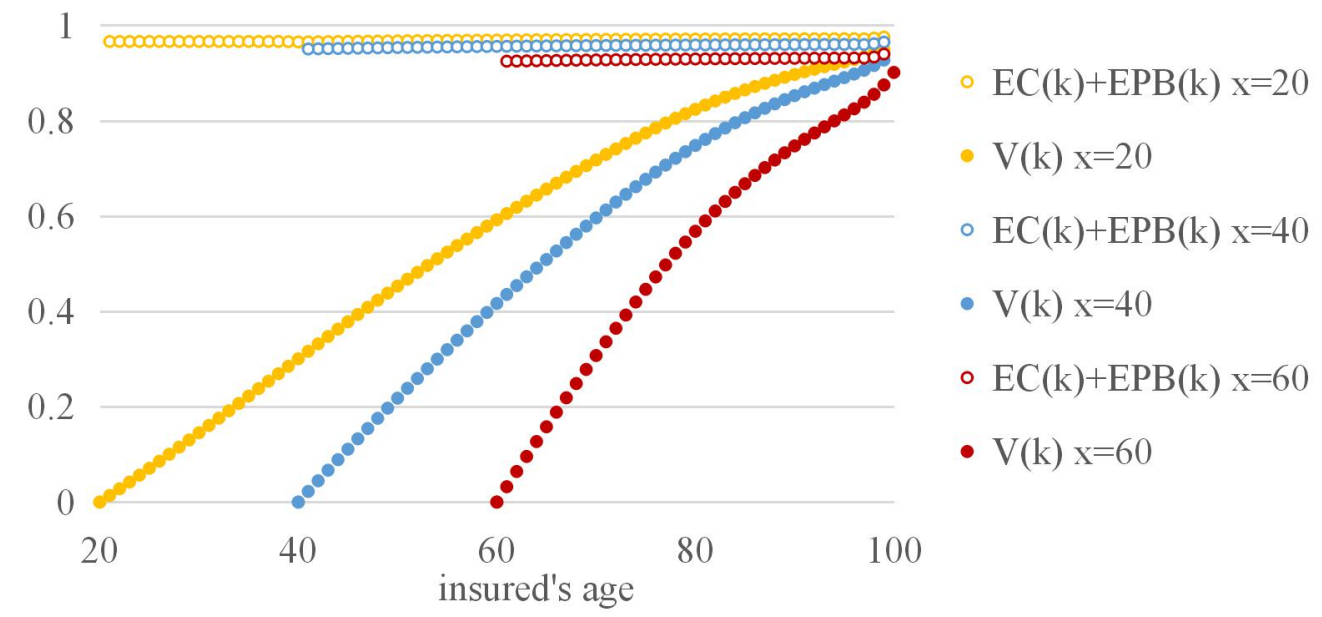

Source: own elaboration.

Figure 6: Ranges of investor's expected profits for the whole life insurance (insured: 20, 40, 60 year old man).

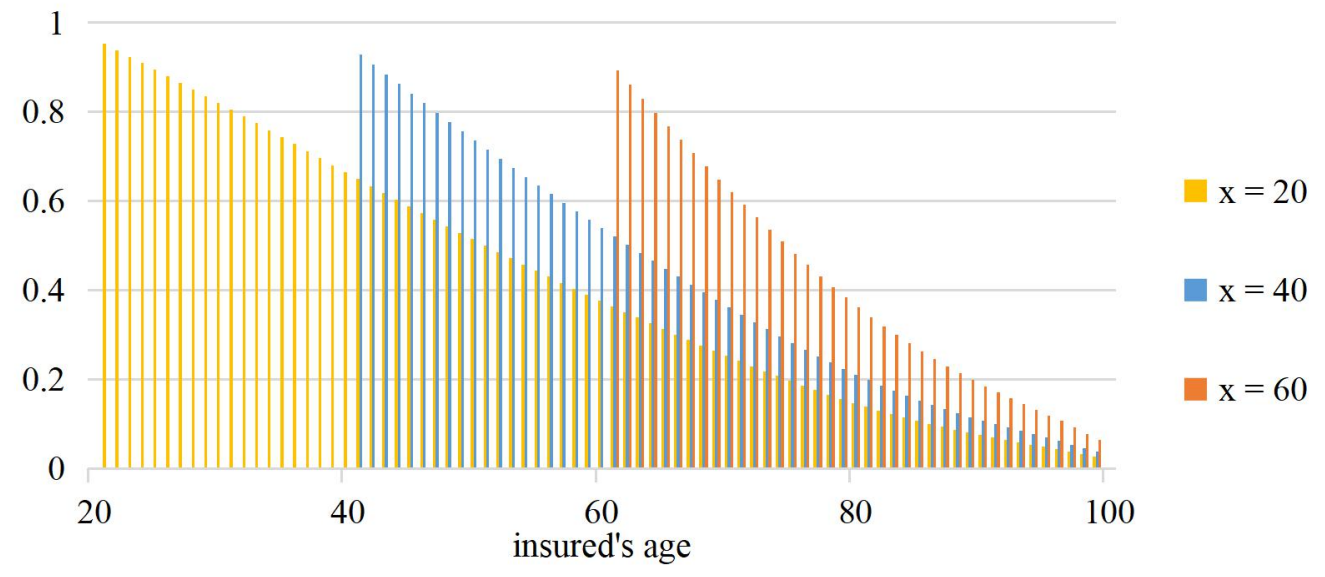

Source: own elaboration.

\section{Conclusion}

In the paper we studied the influence of the moment of falling ill (compared to the age and sex of the insured and duration of insurance) onto the expected profit of the viatical company (investor). For this purpose, we proposed a multiple state model for designing and implementing viatical contracts. Based on a modified multiple state model we derived matrix formulas both for the range of the viatical settlement payment and an investor's expected profit.

Based on the actual data for the Lower Silesian Voivodship in Poland, we cost viatical contracts when the insured has lung cancer with metastases. The value of viatical settlement 
payment depends on the age of the insured and the length of premiums payment at the moment of falling ill. Moreover, the calculations show a greater impact of an insured sex and age on the amount of the investor's expected profit. The shorter the insurance contract lasts, the less money to repurchase the right to death benefits may be offered by the investor, which means higher expected profits for him. In case of lung cancer the expected profit of the investor is lower for men than for women (except of insurance contracts, when premiums are realized through the whole insurance period).

The results achieved in the article can be used to analyze the profitability of resale rights to death benefits from the insured point of view in case of individual contracts and marriage life insurances.

All calculations are made by the use of the authors' own programs written in $\mathrm{C}++$.

\section{Acknowledgements}

The support of the grant scheme NON-STANDARD MULTILIFE INSURANCE PRODUCTS WITH DEPENDENCE BETWEEN INSURED 2013/09/B/HS4/00490 is gladly acknowledged.

\section{References}

[1] BOWERS N.L., GERBER H.U., HICHMANN J.C., JONES D.A., NESBITT C.J. 1986. Actuarial Mathematics. Illinois: Society of Actuaries.

[2] CHRISTIANSEN M.C. 2012. Multistate models in health insurance. Asta-Advances in Statistical Analysis, 2012, vol. 96, iss. 2, pp. 155-186.

[3] DĘBICKA J. 2013. An approach to the study of multistate insurance contracts. Appl. Stochastic Models Bus. Ind., 2013, vol. 29, iss. 3, pp. 224-240.

[4] DĘBICKA J., HEILPERN. S., MARCINIUK A. 2016. Profitability of marriage insurance contracts. 19-th AMSE. Applications of Mathematics in Economics. International Scientific Conference: International Scientific Conference: Banská Štiavnica, Slovakia, 31 Aug. - 4 Sep. 2016. Conference Proceedings

http://amse.umb.sk/proceedings/DebickaHeilpernMarciniuk.pdf

[5] DĘBICKA J., MARCINIUK A., ZMYŚLONA B. 2015. Combination Reverse Annuity Contract and Critical Illness Insurance. 18-th AMSE. Applications of Mathematics in Economics. International Scientific Conference: Jindřichův Hradec 2-6 September, 2015. Conference Proceedings. http://amse2015.cz/proceedings.

[6] DĘBICKA J., ZMYŚLONA B. (a), Modelling of lung cancer survival data for critical illness insurances. Available at arXiv:1602.08696

[7] DĘBICKA J., ZMYŚLONA B. (b), Premium valuation for a multiple state model containing manifold premium-paid states. Available at arXiv:1701.07218

[8] DĘBICKA J., ZMYŚLONA B. (c), Construction of Multi-State Life Tables for Critical Illness Insurance - Influence of Age and Sex on the Incidence of Health Inequalities. Silesian Statistical Review No. 14, 2016, pp. 41-63.

[9] DJEHJCHE B. 2011. Actuarial mathematics for life contingent risks. Scandinavian Actuarial Journal, 2011, iss. 4, pp. 318-328.

[10]HABERMAN S., PITACCO E. 1999. Actuarial Models for Disability Insurance, Chapman \& Hall/CRC.

[11]KIM H.S. 2009. Life settlement in US. Research report in KIDI

[12]TRINKAUS J., GIACALONE J.A. 2002. Entrepreneurial "Mining" of the Dying: Viatical Transactions, Tax Strategies and Mind Games. Journal of Business Ethics 36: 187-194, 2002. Kluwer Academic Publishers. Printed in the Netherlands. 